\title{
Maternal and fetal outcomes in pregnant women with hyperemesis gravidarum
}

\author{
Sangeeta Parihar ${ }^{1}$, Swatantar Singh ${ }^{2 *}$
}

\begin{abstract}
${ }^{1}$ Department of Gynecology, ${ }^{2}$ Department of Pediatrics, Government District Hospital, Rajouri, Jammu and Kashmir,
\end{abstract} India

Received: 11 January 2019

Accepted: 25 January 2019

\section{*Correspondence:}

Dr. Swatantar Singh,

E-mail: singhswatantar@gmail.com

Copyright: (c) the author(s), publisher and licensee Medip Academy. This is an open-access article distributed under the terms of the Creative Commons Attribution Non-Commercial License, which permits unrestricted non-commercial use, distribution, and reproduction in any medium, provided the original work is properly cited.

\begin{abstract}
Background: Hyperemesis gravidarum (HG) is associated with maternal weight loss, nutritional deficiencies, fluid and electrolyte abnormalities, which may lead to adverse fetal and maternal outcomes. The purpose of this study was to evaluate the relationship of hyperemesis gravidarum to maternal and foetal outcomes.

Methods: A hospital-based prospective observational study was carried out. All patients with singleton pregnancy diagnosed as / history of hyperemesis gravidarum the current pregnancy was included in the study. The pregnant women with multiple pregnancy, molar pregnancy, presence of pre-gestational diabetes, pre-gestational hypertension, and other causes of nausea such as appendicitis and pyelonephritis were excluded from the study.

Results: 36 pregnant women with prevalence rate of $3.28 \%$ have been found to be suffering from HG. Almost half $(17,47.22 \%)$ of the pregnant women with HG had age less than 25 years. The significant association (p-value: 0.0099 ) has been found between parity and smoking with HG. HG was significantly associated with low birth weight (p-value: 0.0133); small for gestational age (SGA) (p-value: 0.0316); APGAR score $<7$ after 1 minute (p-value: 0.0060); and APGAR score <7 after 5 minutes (p-value: 0.0006). There is no association found between mode of delivery, gestational diabetes, and pregnancy-induced hypertension with HG.
\end{abstract}

Conclusions: HG can adversely affect fetal as well as maternal, though not significant, pregnancy outcomes.

Keywords: Adverse pregnancy outcomes, Fetal outcomes, Hyperemesis gravidarum, Maternal outcomes

\section{INTRODUCTION}

Nausea and vomiting are among the commonest experiences by women during pregnancy. It may affect $70-80 \%$ of all pregnant women. ${ }^{1}$ Majority of the pregnant women experiences nausea and vomiting mostly during the first trimester. Very limited number of limited women have a prolonged course with symptoms extending until delivery. ${ }^{2}$ Most of the pregnant women with nausea and vomiting can self-manage their symptoms by avoiding triggering factors/food and adequate oral hydration. ${ }^{3}$ The remaining pregnant women have more severe and protracted symptoms which leads to physical and psychosocial sequelae. ${ }^{4}$ This type of the most severe form of nausea and vomiting in pregnancy (NVP) is referred to as hyperemesis gravidarum $(\mathrm{HG}) .^{5}$

According to World Health Organization, Hyperemesis gravidarum $(\mathrm{HG})$ is characterised by severe NVP starting before the 22nd week of gestation and can occur with or without metabolic disturbances. ${ }^{6} \mathrm{HG}$ is the most common cause of hospitalization during the first half of pregnancy and is second only to preterm labor for hospitalizations in overall pregnancy in USA. ${ }^{7}$ The prevalence of HG may varies from $0.3 \%$ to $3 \%$ of pregnancies depending on ethnic variation in study populations. ${ }^{7}$ Pregnant women 
of Western Europe had the lowest prevalence $(0.8 \%)$ of $\mathrm{HG}$, whereas those of India and Sri Lanka had the highest prevalence $(3.2 \%)$ of $\mathrm{HG}^{8}$ Despite extensive research in this field, the mechanism of the disease is largely unknown. ${ }^{7}$

There are literatures available, which associate HG with adverse fetal pregnancy outcomes like low birth weight, pre-term birth, and small-for-gestational age (SGA) infants. $^{9-11}$

But one of the same systematic review also not able to identified any association of $\mathrm{HG}$ with Apgar scores, congenital anomalies, or perinatal death. ${ }^{9}$ HG causes emotional and psychological disturbances and can grossly adversely affect quality of life of pregnant women. HG can also affect behavioural and cognitive function, work capacity, household activities and interaction with children of pregnant women. ${ }^{12,13} \mathrm{HG}$ is associated with maternal weight loss, nutritional deficiencies, fluid and electrolyte abnormalities, which may lead to adverse fetal and maternal outcomes. ${ }^{14,15}$

The purpose of this study was to evaluate the relationship of hyperemesis gravidarum to maternal and foetal outcomes.

\section{METHODS}

A hospital-based prospective observational study was carried out to analyse the impact of hyperemesis gravidarum on the maternal and fetal outcome. The study was conducted in Department of Obstetrics and Gynaecology, Sri Maharaja Gulab Singh (SMGS) Hospital, Jammu and Gastroenterology section of Department of Medicine, Govt. Medical College, Jammu between July 2010 to June 2012. The study was approved by Institutional Ethics Committee. Written informed consent was obtained from patient before enrolling them into the study.

\section{Inclusion criteria}

- All patients with singleton pregnancy diagnosed as / history of hyperemesis gravidarum.

- The pregnant women with one or more antepartum hospitalizations for emesis, the first hospitalization must had occurred before 24 weeks of gestation considered as hyperemetic pregnancies.

\section{Exclusion criteria}

- The pregnant women with multiple pregnancy, molar pregnancy, presence of pre-gestational diabetes, pregestational hypertension, and other causes of nausea such as appendicitis and pyelonephritis.

All the patients with hyperemesis gravidarum were admitted, examined for signs of dehydration, and were treated with intravenous fluids and antiemetics. Patients were discharged after brief stay of 3-4 days in hospital after symptomatic improvement tolerating oral food intake. These patients were followed up throughout pregnancy and the maternal and fetal outcome were evaluated.

Birth weight; small for gestational age (SGA: the bottom tenth percentile for weight according to week of gestation and gender); pre-term delivery (birth before 37 weeks of gestation); 1 and 5-minute APGAR score were assigned as fetal outcomes. While, mode of delivery (caesarean section, vaginal), gestational diabetes, and pregnancyinduced hypertension were assigned as the maternal outcomes.All the data were recorded in case record form. The data was entered in the excel sheet. The data was analysed using descriptive statistics. The test variables were compared using Chi-square test for qualitative variables and Student's test for quantitative variables. The $p$-value $<0.05$ was considered statistically significant for difference and association between variables.

\section{Statistical analysis}

Statistical analysis was performed using SPSS 16.0 software. Unpaired t-test was used to analyze continuous data. Categorical data was compared using Chi-square test. $\mathrm{P}<0.05$ was taken as statistically significant. Relative risk was calculated for abnormal UA PI, UA RI, UA S/D, MCA PI and cerebral-umbilical PI ratio. Multivariate regression was used to analyze effect of multiple variables.

\section{RESULTS}

Total 1100 pregnant women were screened during the study period. Based on the defined criteria for hyperemesis gravidarum $(\mathrm{HG})$ for the present study, 36 pregnant women have been found to be suffering from HG. This give the overall prevalence of $3.28 \%$ of $\mathrm{HG}$ for the present study (Figure 1).

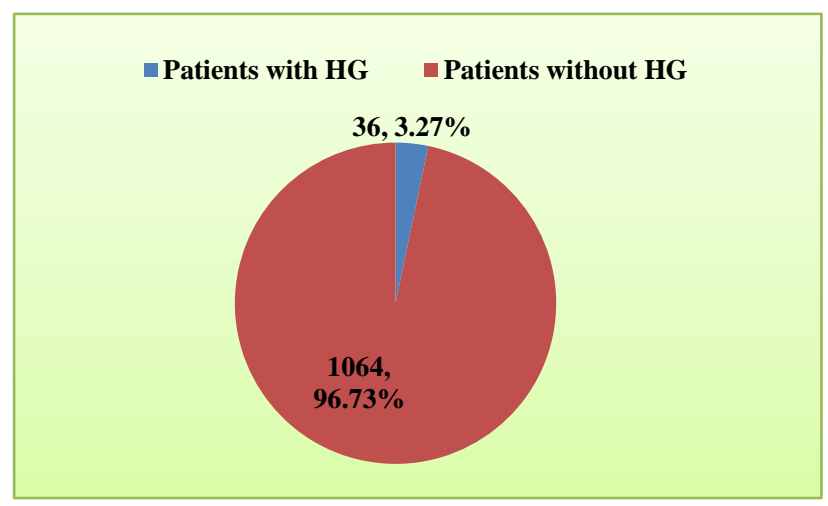

Figure 1: Prevalence of hyperemesis gravidarum (HG).

The most frequently affected (14, 38.89\%) age-group with hyperemesis gravidarum was 20-24 years followed by age groups of 25-29 years $(10,27.78 \%)$ and $30-34$ 
years $(7,19.44 \%)$. The age group of $20-24$ years significantly (p-value: 0.0000) associated with development of hyperemesis gravidarum. Majority of pregnant women with hyperemesis gravidarum was of primipara.
The significant association (p-value: 0.0099) has been found between parity and hyperemesis gravidarum. Smoking habit is also significantly (p-value: 0.0132) associated with development of hyperemesis gravidarum (Table 1).

Table 1: Background characteristics of the study participants.

\begin{tabular}{|c|c|c|c|c|c|c|}
\hline \multirow{2}{*}{ Characteristics } & \multicolumn{2}{|c|}{ All patients ( $N=1100)$} & \multicolumn{2}{|c|}{ HG $(\mathbf{N}=36)$} & \multirow{2}{*}{ Chi-square value } & \multirow{2}{*}{ p-value } \\
\hline & $\mathbf{N}$ & $\%$ & $\mathbf{N}$ & $\%$ & & \\
\hline \multicolumn{7}{|l|}{ Maternal age } \\
\hline$<20$ years & 14 & 1.27 & 3 & 8.33 & 11.7890 & $0.0006 * *$ \\
\hline $20-24$ years & 122 & 11.09 & 14 & 38.89 & 25.5600 & $0.0000 * *$ \\
\hline $25-29$ years & 436 & 39.64 & 10 & 27.78 & 1.9404 & 0.1636 \\
\hline $30-34$ years & 395 & 35.91 & 7 & 19.44 & 3.4442 & 0.0635 \\
\hline$>35$ years & 133 & 12.09 & 3 & 0.47 & 2.0758 & 0.4944 \\
\hline \multicolumn{5}{|l|}{ Parity } & \multirow{3}{*}{6.6389} & \multirow{3}{*}{$0.0099 *$} \\
\hline Primipara & 524 & 47.64 & 25 & 69.44 & & \\
\hline Multipara & 576 & 52.36 & 11 & 30.56 & & \\
\hline \multicolumn{5}{|l|}{ Smoking habit } & \multirow{3}{*}{6.1393} & \multirow{3}{*}{$0.0132 *$} \\
\hline Non-smokers & 1048 & 95.27 & 31 & 86.11 & & \\
\hline Smokers & 52 & 4.73 & 5 & 13.89 & & \\
\hline
\end{tabular}

HG: hyperemesis gravidarum; ${ }^{*}$ p-value $<0.05$ : significant difference; $* *$ p-value $<0.001$ : significant difference

Table 2: Fetal outcomes of pregnancy in study participants.

\begin{tabular}{|c|c|c|c|c|c|c|}
\hline \multirow{3}{*}{ Fetal outcomes } & \multirow{2}{*}{\multicolumn{2}{|c|}{$\begin{array}{l}\text { All patients } \\
(\mathbf{N}=\mathbf{1 1 0 0})\end{array}$}} & \multicolumn{2}{|c|}{ HG } & \multirow{3}{*}{ Chi-square value } & \multirow{3}{*}{ p-value } \\
\hline & & & $(\mathbf{N}=$ & & & \\
\hline & $\mathbf{N}$ & $\%$ & $\mathbf{N}$ & $\%$ & & \\
\hline Low birth weight & 366 & 33.27 & 19 & 52.78 & 6.1306 & $0.0133 *$ \\
\hline SGA & 162 & 14.73 & 10 & 27.78 & 4.6209 & $0.0316 *$ \\
\hline Pre-term & 314 & 28.55 & 15 & 41.67 & 2.9171 & 0.0876 \\
\hline APGAR score- 1 minute $<7$ & 62 & 5.64 & 6 & 16.67 & 7.5365 & $0.0060 *$ \\
\hline APGAR score- 5 minute $<7$ & 14 & 1.27 & 3 & 8.33 & 11.7890 & $0.0006 * *$ \\
\hline
\end{tabular}

HG: hyperemesis gravidarum; * p-value $<0.05$ : significant difference; $* *$ p-value $<0.001$ : significant difference

Table 3: Maternal outcomes of pregnancy in study participants.

\begin{tabular}{|c|c|c|c|c|c|c|}
\hline \multirow{3}{*}{ Maternal outcomes } & \multirow{2}{*}{\multicolumn{2}{|c|}{$\begin{array}{l}\text { All patients } \\
(\mathbf{N}=\mathbf{1 1 0 0})\end{array}$}} & \multirow{2}{*}{\multicolumn{2}{|c|}{$\begin{array}{l}\mathrm{HG} \\
(\mathrm{N}=36)\end{array}$}} & \multirow{3}{*}{ Chi-square value } & \multirow{3}{*}{ p-value } \\
\hline & & & & & & \\
\hline & $\mathbf{N}$ & $\%$ & $\mathbf{N}$ & $\%$ & & \\
\hline \multicolumn{7}{|l|}{ Mode of delivery } \\
\hline Caesarean section & 378 & 34.36 & 10 & 27.78 & \multirow{2}{*}{0.6723} & \multirow{2}{*}{0.4123} \\
\hline Vaginal & 722 & 65.64 & 26 & 72.22 & & \\
\hline Gestational diabetes & 62 & 5.64 & 3 & 8.33 & 0.2959 & 0.5865 \\
\hline Pregnancy-induced hypertension & 48 & 4.36 & 3 & 8.33 & 0.9757 & 0.3233 \\
\hline
\end{tabular}

HG: hyperemesis gravidarum

Fetal outcomes of pregnancy were depicted in table 2. According to table 2, development of hyperemesis gravidarum was significantly associated with low birth weight (p-value: 0.0133); small for gestational age (SGA) (p-value: 0.0316); APGAR score $<7$ after 1 minute (pvalue: 0.0060); and APGAR score $<7$ after 5 minutes (pvalue: 0.0006$)$.
There is no association found between pre-term delivery and hyperemesis gravidarum. According to table 3 regarding maternal outcomes of pregnancy, no statistically significant association has been detected for gestational diabetes, and pregnancy-induced hypertension with hyperemesis gravidarum. Caesarean delivery rate in 
pregnant women with hyperemesis gravidarum were similar to other pregnant women during study period.

\section{DISCUSSION}

This prospective observational hospital-based study presents a comprehensive profile on the maternal and fetal outcome in pregnant women with hyperemesis gravidarum. Out of the total 1100 pregnant women were screened during the study period, 36 pregnant women have been found to be suffering from $\mathrm{HG}$ with prevalence of $3.28 \%$. Different large population studies suggest the ethnic variation in the incidence of $\mathrm{HG} .^{7}$ In a study based on the Medical Birth Registry of the of Norway from 1967-2005, overall prevalence of $0.9 \%$ has been found for HG. ${ }^{16}$ According to ethnicity, prevalence of HG found in $2.2 \%$ of Pakastani women and $1.9 \%$ of Turkish women, both more than twice the incidence of $0.9 \%$ in Norwegian women. ${ }^{16}$ Asian populations tend to have higher prevalence of HG. The prevalence rate of $3.9 \%$ and $3.6 \%$ has been found out in a Malaysian study and an Eastern Asian population study, respectively. ${ }^{17,18}$ Pregnant women of Western Europe had the lowest prevalence $(0.8 \%)$ of $\mathrm{HG}$, whereas those of India and Sri Lanka had the highest prevalence $(3.2 \%)$ of $\mathrm{HG}^{8}$

The most frequently affected age-group with hyperemesis gravidarum was of 20-24 years. Almost half (17, 47.22\%) of the pregnant women with $\mathrm{HG}$ had age less than 25 years in the present study. The age group of 20-24 years significantly associated with development of hyperemesis gravidarum. In the Norwegian study, maternal age of 20 24 years was more likely to develop $\mathrm{HG}^{8}{ }^{8}$ The prevalence of HG gradually decreases with advancing age. ${ }^{19}$ Majority of pregnant women with hyperemesis gravidarum was of primipara. The significant association has been found between parity and HG in the present study. Similar parity preponderance was found in many other studies including the large Norwegian cohort study. ${ }^{8,20}$ The multiparous women can cope up the symptoms much easier based on their previous experience of pregnancy/s. Smoking habit is also significantly associated with development of hyperemesis gravidarum. $\mathrm{HG}$ is a multifactorial condition and has been associated with various risk factors. ${ }^{21}$ Women with HG are more likely to be younger, primiparous, and alcoholics. $^{22,23}$ But smoking do not appear to differ significantly between women with $\mathrm{HG}$ and those without. $^{23}$

In the present study, development of hyperemesis gravidarum was significantly associated with low birth weight; small for gestational age (SGA); APGAR score < 7 after 1 minute; and APGAR score $<7$ after 5 minutes. There is no association found between pre-term delivery and hyperemesis gravidarum. Two large cohort studies reported that pregnant women with HG had low birth weight, and an increased rate of being SGA babies. ${ }^{10,24}$ In a 10-year study of Norway, Vikanes et al. observed low birthweight among women with $\mathrm{HG}^{20} \mathrm{~A}$ Web site registry based study, performed by Fejzo et al., involving 819 women with $\mathrm{HG}, 8 \%$ of the women reported low birth weight infants. ${ }^{25} \mathrm{HG}$ has been reported to be associated with an increased risk for adverse fetal outcomes, like, low birth weight, preterm birth, and small-for-gestational age infants.9-11 A recent systematic review failed to identify association with APGAR scores, congenital anomalies, or perinatal death. ${ }^{9}$

Although, higher prevalence of gestational diabetes, and pregnancy-induced hypertension was found out in pregnant women with $\mathrm{HG}$, the present study had found no association between mode of delivery, gestational diabetes, and pregnancy-induced hypertension with HG. Similar complicated pregnancy rates were found in control and HG groups in the study done by Kuru, et al. ${ }^{26}$ The rate of pregnancy-induced hypertension in HG was similar to controls in their study as well as in study of Tan et al. ${ }^{21} \mathrm{HG}$ can be extremely debilitating for pregnant women. It can cause malnutrition, electrolyte imbalances, thrombosis, Wernicke's encephalopathy, depressive illness, and poor pregnancy outcomes. ${ }^{27-29}$

It is important for treating physicians to emphasize on early assessment of nausea and vomiting in pregnancy, which may prevent delay in diagnosis and management of HG. Any new interventions, however, must be shown to be safe from both a maternal and fetal point of view, to be acceptable to mothers, and to be cost-effective for reduction of adverse pregnancy outcomes.

\section{CONCLUSION}

In conclusion, pregnant women with $\mathrm{HG}$ are more likely to be younger and primiparous. HG can adversely affect fetal outcomes - low birth weight; small for gestational age (SGA); APGAR score < 7 after 1 minute; and APGAR score $<7$ after 5 minutes. Not significant but higher prevalence of gestational diabetes, and pregnancyinduced hypertension was found out in pregnant women with HG.

\section{Funding: No funding sources \\ Conflict of interest: None declared}

Ethical approval: The study was approved by the Institutional Ethics Committee

\section{REFERENCES}

1. Lee NM, Saha S. Nausea and vomiting of pregnancy. Gastroenterol Clin North Am. 2011;40(2):309-34, vii.

2. Lu QB, Wang ZP, Gao LJ, Gong R, Sun X, Wang M, et al. Nausea and vomiting in early pregnancy and the risk of neural tube defects: a case-control study. Sci Rep. 2015;5:7674.

3. Jarvis S, Nelson-Piercy C. Management of nausea and vomiting in pregnancy. BMJ 2011;342:d3606.

4. Attard CL, Kohli MA, Coleman S, Bradley C, Hux M, Atanackovic G, et al. The burden of illness of 
severe nausea and vomiting of pregnancy in the United States. Am J Obstet Gynecol 2002;186(5):S22-7.

5. O’Donnell A, McParlin C, Robson SC, Beyer F, Moloney E, Bryant A, et al. Treatments for hyperemesis gravidarum and nausea and vomiting in pregnancy: a systematic review and economic assessment. Health Technol Assess. 2016;20(74):126.

6. World Health Organization (2004) ICD-10, Chapter $\mathrm{XV}$, Pregnancy, childbirth and the puerperium (O00O99), Other maternal disorders predominantly related to pregnancy (O20-O29). World Health Organization. Available at http://apps.who.int/classifications/apps/icd/icd10onli ne2004/fr-icd.htm?go20.htm+.

7. London V, Grube S, Sherer DM, Abulafia O. Hyperemesis Gravidarum: A Review of Recent Literature. Pharmacol. 2017;100(3-4):161-71.

8. Vikanes A, Grjibovski AM, Vangen S, Magnus P. Variations in prevalence of hyperemesis gravidarum by country of birth: a study of 900,074 pregnancies in Norway, 1967-2005. Scand J Public Health. 2008;36(2):135-42.

9. Veenendaal MV, van Abeelen AF, Painter RC, van der Post JA, Roseboom TJ. Consequences of hyperemesis gravidarum for offspring: a systematic review and meta-analysis. BJOG. 2011;118(11):1302-13.

10. Bailit JL. Hyperemesis gravidarium: Epidemiologic findings from a large cohort. Am J Obstet Gynecol. 2005;193(3 Pt 1):811-4.

11. Dodds L, Fell DB, Joseph KS, Allen VM, Butler B. Outcomes of pregnancies complicated by hyperemesis gravidarum. Obstet Gynecol. 2006;107(2 Pt 1):285-92.

12. Poursharif B, Korst LM, MacGibbon KW, Fejzo MS, Romero R, Goodwin TM. Elective pregnancy termination in a large cohort of women with hyperemesis gravidarum. Contraception 2007;76(6):451-6.

13. Mazzotta P, Maltepe C, Navioz Y, Magee LA, Koren G. Attitudes, management and consequences of nausea and vomiting of pregnancy in the United States and Canada. Int $\mathbf{J}$ Gynaecol Obstet 2000;70(3):359-65.

14. Eliakim R, AbulaWa O, Sherer DM. Hyperemesis gravidarum: a current review. Am J Perinatol. 2000;17(4):207-18.

15. Hod M, Orvieto R, Kaplan B, Friedman S, Ovadia J. Hyperemesis gravidarum. A review. J Reprod Med. 1994;39(8):605-12.

16. Grjibovski AM, Vikanes A, Stoltenberg C, Magnus P. Consanguinity and the risk of hyperemesis gravidarum in Norway. Acta Obstet Gynecol Scand. 2007;87(1):20-5.
17. Tan PC, Jacob R, Quek KF, Omar SZ. The fetal sex ratio and metabolic, biochemical, haematological and clinical indicators of severity of hyperemesis gravidarum. BJOG. 2006;113(6):733-7.

18. Matsuo K, Ushioda N, Nagamatsu M, Kimura T. Hyperemesis gravidarum in Eastern Asian population. Gynecol Obstet Invest. 2007;64(4):2136.

19. Depue RH, Bernstein L, Ross RK, Judd HL, Henderson BE. Hyperemesis gravidarum in relation to estradiol levels, pregnancy outcome, and other maternal factors: a seroepidemiologic study. Am J Obstet Gynecol. 1987;156(5):1137-41.

20. Vikanes ÅV, Støer NC, Magnus P, Grjibovski AM. Hyperemesis gravidarum and pregnancy outcomes in the Norwegian Mother and Child Cohort - a cohort study. BMC Pregnancy Childbirth. 2013;13(1):169.

21. Tsang IS, Katz VL, Wells SD. Maternal and fetal outcomes in hyperemesis gravidarum. Int J Gynaecol Obstet. 1996;55(3):231-5.

22. Sanu O, Lamont RF. Hyperemesis gravidarum: pathogenesis and the use of antiemetic agents. Expert Opin Pharmacother. 2011;12(5):737-48.

23. Roseboom TJ, Ravelli AC, van der Post JA, Painter RC. Maternal characteristics largely explain poor pregnancy outcome after hyperemesis gravidarum. Eur J Obstet Gynecol Reprod Biol. 2011;156(1):569.

24. Kallen B. Hyperemesis during pregnancy and delivery outcome: a registry study. Eur J Obstet Gynecol Reprod Biol. 1987;26(4):291-302.

25. Fejzo MS, Poursharif B, Korst LM, Munch S, MacGibbon KW, Romero R, et al. Symptoms and pregnancy outcomes associated with extreme weight loss among women with hyperemesis gravidarum. J Womens Health (Larchmt). 2009;18(12):1981-7.

26. Kuru O, Sen S, Akbayır O, Goksedef BP, Ozsürmeli M, Attar E, et al. Outcomes of pregnancies complicated by hyperemesis gravidarum. Arch Gynecol Obstet. 2012;285(6):1517-21.

27. Verberg MF, Gillott DJ, Al-Fardan N, Grudzinskas JG. Hyperemesis gravidarum, a literature review. Hum Reprod Update. 2005;11(5):527-39.

28. Weigel RM, Weigel MM. Nausea and vomiting of early pregnancy and pregnancy outcome. A metaanalytical review. $\mathrm{Br} \mathrm{J}$ Obstet Gynaecol. 1989;96(11):1312-8.

29. Gross S, Librach C, Cecutti A. Maternal weight loss associated with hyperemesis gravidarum: a predictor of fetal outcome. Am J Obstet Gynecol. 1989;160(4):906-9.

Cite this article as: Parihar S, Singh S. Maternal and fetal outcomes in pregnant women with hyperemesis gravidarum. Int J Reprod Contracept Obstet Gynecol 2019;8:901-5 